\title{
Clinical Prediction Rule for Bacteremia Among Patients with Pyelonephritis and Hospitalization Judgment: Chi-Squared Automatic Interaction Detector (CHAID) Decision Tree Analysis Model
}

\section{Sayato Fukui ( $\nabla$ sfukui@juntendo.ac.jp )}

Juntendo Daigaku - Hongo Campus: Juntendo Daigaku https://orcid.org/0000-0002-1658-2223

Akihiro Inui

Juntendo University: Juntendo Daigaku

Mizue Saita

Juntendo University: Juntendo Daigaku

Daiki Kobayashi

Saint Luke's Hospital: Saint Luke's

Toshio Naito

Juntendo University: Juntendo Daigaku

\section{Research article}

Keywords: Pyelonephritis, Bacteremia, Risk factors, CHAID analysis, Predictive rule

Posted Date: July 8th, 2021

DOI: https://doi.org/10.21203/rs.3.rs-684788/v1

License: (c) (1) This work is licensed under a Creative Commons Attribution 4.0 International License.

Read Full License 


\section{Abstract}

Background: Positive risk factors for bacteremia among patients with pyelonephritis have not been defined using a Chi-Squared Automatic Interaction Detector (CHAID) Decision Tree Analysis Model.

Purpose: We sought to identify predictive factors for bacteremia among patients with pyelonephritis and therefore which patients need hospitalization.

Methods: This retrospective cross-sectional survey was performed at the Juntendo University Nerima Hospital, Tokyo, Japan and comprised all patients with pyelonephritis from whom blood cultures were taken from January 1, 2010 to July 31, 2020. At the time of blood culture sample collection, clinical information was obtained from medical charts, along with vital signs, quick Sequential Organ Failure Assessment (qSOFA), subjective symptoms, objective physical findings, laboratory findings, and results of blood and urine cultures. Factors potentially predictive of bacteremia among patients with pyelonephritis were analyzed using the Student's t-test or chi-squared test and the CHAID decision tree analysis model.

Results: A total of 198 patients (male:female, 60 (30.3\%):138 (69.7\%), ages (mean \pm SD) 74.69 \pm 15.27 years) were included in this study, of whom $92(46.4 \%)$ had positive blood culture results. The CHAID decision tree analysis revealed that patients with White blood cell $>21,000 / \mu \mathrm{L}$ had a quite-high-risk (89.5\%) of developing bacteremia. Patients with White blood cell $\leq 21,000 / \mu \mathrm{L}$ plus Chill plus Aspartate aminotransferase $>19 \mathrm{IU} / \mathrm{L}$ represented a high-risk group (69.0\%). Conversely, patients with White blood cell $\leq 21,000 / \mu \mathrm{L}$ plus non-Chill plus Albumin $>3.60 \mathrm{~g} / \mathrm{dL}$ were at a low risk $(16.3 \%)$ of developing bacteremia.

Conclusion: Our results emphasize the importance of hospitalization among high-risk and quite-high-risk groups of pyelonephritis patients.

\section{Introduction}

Pyelonephritis is a common disease encountered by many physicians. For example, in the United States, there are approximately 250,000 cases of acute pyelonephritis each year, resulting in more than 100,000 hospitalizations [1]. The management guidelines for urinary tract infections (UTIs) in the United States and Japan recommend that patients with mild pyelonephritis be treated in an outpatient clinic [2,3], while patients with severe disease should be considered for hospitalization and initial administration of intravenous antibiotics [4]. As for patients with pyelonephritis accompanied by bacteremia, hospitalization is preferable, given that severe pyelonephritis accompanied by bacteremia has a mortality rate of $10-20 \%[5,6]$. However, in practice, the results of blood cultures typically are not available on the same day that a patient is diagnosed with pyelonephritis; because results are expected on a later day, patients with pyelonephritis may be hospitalized, as a precautionary measure, before blood culture results are obtained. It would be useful to be able to predict the positive results of blood cultures on the same day as patients are diagnosed with pyelonephritis. Based on our preliminary research, blood culture- 
positive causative diseases often are diagnosed as pyelonephritis for patients being seen in departments of general medicine [7]. Furthermore, other preliminary research has indicated that older age, positive urinary nitrite test results, and chills tend to be seen in patients who have pyelonephritis accompanied by bacteremia [8]. However, the quick Sequential Organ Failure Assessment (qSOFA), which now is used widely, was not incorporated as part of these preliminary researches [9]. Furthermore, a score classification system for recommendation of hospitalization does not exist for pyelonephritis, in contrast to our experience with other diseases (e.g., CURB-65 for patients with pneumonia) [10-12]. As described above, the patients with bacteremia, among those with pyelonephritis, typically require hospitalization; there would be a great advantage to a classification system for identifying the need to hospitalize patients with pyelonephritis who are at increased risk of developing bacteremia.

To identify predictive factors for bacteremia among patients diagnosed with pyelonephritis, we compared clinical parameters between patients positive and negative for bacteremia among cases diagnosed with pyelonephritis, with the goal of establishing which patients with pyelonephritis should be hospitalized.

\section{Methods}

\section{Study Design and Study Population}

We recruited patients who were diagnosed with pyelonephritis from January 1, 2010 to July 31, 2020. This retrospective, cross-sectional study was performed at Juntendo University Nerima Hospital, a 400bed university-affiliated hospital in Tokyo, Japan. We excluded patients from whom blood cultures had not been taken and patients who had already (as part the same admission) received an antimicrobial agent prior to blood culture submission (given possible effects on blood culture results). We also excluded patients with obstructive pyelonephritis due to a calculus or tumor and those who had undergone urgent stenting, because these individuals were hospitalized regardless of the results of blood cultures. Bacteremia in patients with pyelonephritis was defined as the detection of identical causative bacteria from both blood and urine cultures. Furthermore, more than 3 doctors were involved in each diagnosis. Clinical information extracted by chart review included (but was not limited to) the following: vital signs including qSOFA, subjective symptoms, objective physical findings, laboratory findings, and results of blood and urine cultures.

\section{Statistical analysis}

Patients' characteristics were compared between those with bacteremia and those without bacteremia

by using $t$-test for continuous data or by the chi-squared test for categorical data. Then, we applied ChiSquared Automatic Interaction Detector (CHAID) decision tree analysis to identify risk factors for bacteremia. The CHAID decision tree analysis is a data-mining technique $[13,14]$ with a salient advantage of advanced graphic presentation for interpretation [15]. The CHAID enabled the consideration of whole variables, the effective partitioning of continuous data, and construction of decision trees by use of a forward-stopping or -pruning rule [16]. Moreover, CHAID is the only model that permits the 
formulation of multiple nodes [15]. Unlike other techniques, CHAID permits the significance level to be adjusted for the number of comparisons. The CHAID has been applied previously in the medical field [17, 18] and has been shown to be superior to logistic analysis [19]. In addition, prediction rules with the CHAID model are visibly intuitive and easy to interpret in clinical settings. Mother and daughter nodes were set as 25 and 15, respectively. In order to compare two prediction, qSOFA and CHAID, the goodnessof-fit of the model was examined by the receiver operating characteristic (ROC) curve and its area under the curve (AUC). All statistical analyses were performed using SPSS software, version 22 (IBM, Tokyo, Japan).

This study was approved by the Ethics Committee of Juntendo University Nerima Hospital (Approval Number 2020054).

\section{Results}

A total of 261 patients were diagnosed with pyelonephritis during the study period. Within this population, $27(10.3 \%)$ patients were excluded because of their urgent stenting for obstructive pyelonephritis, and 36 (13.8\%) patients were excluded due to the precedent administration of an antimicrobial agent before blood culturing. As shown in Table 1, a total of 198 patients (male:female, 60 (30.3\%):138 (69.7\%); mean \pm SD age, $74.69 \pm 15.27$ years) were included in this study and 92 patients $(46.4 \%)$ had bacteremia. Table 1 also shows patient characteristics in the two groups (with and without bacteremia) and the results of bivariable analysis. Chill, Neutrophils, Band-form neutrophils, Lymphocytes, Blood urea nitrogen, total protein, Albumin, Lactate dehydrogenase, C-reactive protein, and Hemoglobin A1c were all related to bacteremia. 
Table 1

Patient characteristics

Variables

\section{Demographic factors}

Age, year, mean $\pm S D$

Female sex, n (\%)

\section{Underlying condition}

Body Mass Index, $\mathrm{kg} / \mathrm{m}^{2}$, mean $\pm \mathrm{SD}$

Cancer bearing, $\mathrm{n}(\%)$

Hemodyscrasia n (\%)

Diabetes mellitus $\mathrm{n}(\%)$

Indwelling urinary catheter, $\mathrm{n}$ (\%)

Neurogenic bladder, n (\%)

Use of immunosuppressive agents, $\mathrm{n}(\%)$

History of pyelonephritis, n (\%)

\section{Symptoms}

Macrohematuria, n (\%)

Pain on urination, $\mathrm{n}(\%)$

Back pain, $\mathrm{n}(\%)$

Chill, n (\%)

Vomiting, $\mathrm{n}(\%)$

Nausea, $\mathrm{n}(\%)$

Diarrhea, n (\%)
Total

$n=198$
$74.69 \pm$

15.27

$138(69.6 \%)$
Bacteremia

$\mathrm{n}=92$
Non-

bacteremia

$n=106$ $\begin{array}{ll}\text { Name } & p \\ \text { of test } & \text { value }\end{array}$ 
Total

$n=198$

69(34.8\%)
Non-

bacteremia
Name

of test $p$ value

\section{Clinical sign}

CVA tenderness, n (\%)

$\mathrm{n}=92$

$n=106$

\section{Vital signs}

\begin{tabular}{|c|c|c|c|c|c|}
\hline $\begin{array}{l}\text { Disturbance of consciousness, } \\
n(\%)\end{array}$ & $64(32.3 \%)$ & $31(33.7 \%)$ & $33(31.1 \%)$ & $x^{2}$ & 0.76 \\
\hline Temperature, ${ }^{\circ} \mathrm{C}$, mean $\pm \mathrm{SD}$ & $38.21 \pm 1.19$ & $38.36 \pm 1.32$ & $38.08 \pm 1.94$ & t-test & 0.09 \\
\hline $\begin{array}{l}\text { Systolic blood pressure, } \mathrm{mmHg} \text {, } \\
\text { mean } \pm \mathrm{SD}\end{array}$ & $\begin{array}{l}133.10 \pm \\
26.08\end{array}$ & $\begin{array}{l}134.46 \pm \\
28.05\end{array}$ & $\begin{array}{l}131.90 \pm \\
24.26\end{array}$ & t-test & 0.49 \\
\hline $\begin{array}{l}\text { Diastolic blood pressure, } \\
\mathrm{mmHg} \text {, mean } \pm \text { SD }\end{array}$ & $\begin{array}{l}73.67 \pm \\
16.39\end{array}$ & $\begin{array}{l}72.84 \pm \\
16.59\end{array}$ & $\begin{array}{l}74.40 \pm \\
16.24\end{array}$ & t-test & 0.51 \\
\hline Heart rate, bpm, mean $\pm S D$ & $\begin{array}{l}95.87 \pm \\
18.34\end{array}$ & $\begin{array}{l}97.97 \pm \\
18.19\end{array}$ & $\begin{array}{l}93.96 \pm \\
18.35\end{array}$ & t-test & 0.13 \\
\hline $\begin{array}{l}\text { Respiratory rate, } \min ^{-1}, \mathrm{n} \text {, } \\
\text { mean } \pm S D\end{array}$ & $19.33 \pm 4.09$ & $19.33 \pm 4.24$ & $19.32 \pm 3.97$ & t-test & 0.99 \\
\hline Saturation, $\%$, mean \pm SD & $96.06 \pm 2.89$ & $95.95 \pm 3.01$ & $96.15 \pm 2.79$ & t-test & 0.65 \\
\hline \multicolumn{6}{|l|}{ Laboratory data } \\
\hline $\begin{array}{l}\text { White blood cell counts, } / \mu \mathrm{L} \text {, } \\
\text { mean } \pm \mathrm{SD}\end{array}$ & $\begin{array}{l}12628.28 \pm \\
5926.21\end{array}$ & $\begin{array}{l}13468.48 \pm \\
6935.38\end{array}$ & $\begin{array}{l}11899.06 \pm \\
4801.06\end{array}$ & t-test & 0.06 \\
\hline Neutrophils, \%, mean \pm SD & $86.66 \pm 8.28$ & $90.01 \pm 5.78$ & $83.78 \pm 9.02$ & t-test & <. $001 *$ \\
\hline $\begin{array}{l}\text { Band-form neutrophils, \%, } \\
\text { mean } \pm \text { SD }\end{array}$ & $8.99 \pm 10.62$ & $\begin{array}{l}11.43 \pm \\
10.91\end{array}$ & $6.23 \pm 9.73$ & t-test & $0.04^{\star}$ \\
\hline $\begin{array}{l}\text { Segmented neutrophils, \%, } \\
\text { mean } \pm \text { SD }\end{array}$ & $\begin{array}{l}79.10 \pm \\
13.10\end{array}$ & $\begin{array}{l}80.31 \pm \\
13.11\end{array}$ & $\begin{array}{l}77.73 \pm \\
13.16\end{array}$ & t-test & 0.43 \\
\hline Lymphocytes, $\%$, mean \pm SD & $7.97 \pm 6.39$ & $5.73 \pm 4.34$ & $9.86 \pm 7.22$ & t-test & $<.001 *$ \\
\hline Hemoglobin, $\mathrm{g} / \mathrm{dL}$, mean \pm SD & $12.17 \pm 1.86$ & $12.09 \pm 1.92$ & $12.24 \pm 1.82$ & t-test & 0.58 \\
\hline Platelets, $10^{4} / \mu \mathrm{L}$, mean $\pm \mathrm{SD}$ & $18.44 \pm 7.52$ & $18.20 \pm 8.44$ & $18.64 \pm 6.66$ & t-test & 0.69 \\
\hline $\begin{array}{l}\text { Blood urea nitrogen, } \mathrm{mg} / \mathrm{dL} \text {, } \\
\text { mean } \pm \mathrm{SD}\end{array}$ & $\begin{array}{l}25.29 \pm \\
19.66\end{array}$ & $\begin{array}{l}29.80 \pm \\
24.31\end{array}$ & $\begin{array}{l}21.36 \pm \\
13.40\end{array}$ & t-test & <. $0.01 *$ \\
\hline Creatinine, $\mathrm{mg} / \mathrm{dL}$, mean $\pm \mathrm{SD}$ & $1.37 \pm 1.35$ & $1.47 \pm 1.32$ & $1.28 \pm 1.39$ & t-test & 0.30 \\
\hline
\end{tabular}




\begin{tabular}{|c|c|c|c|c|c|}
\hline Variables & Total & Bacteremia & $\begin{array}{l}\text { Non- } \\
\text { bacteremia }\end{array}$ & $\begin{array}{l}\text { Name } \\
\text { of test }\end{array}$ & \multirow[t]{2}{*}{$\begin{array}{l}p \\
\text { value }\end{array}$} \\
\hline & $n=198$ & $n=92$ & \multicolumn{2}{|l|}{$n=106$} & \\
\hline Total protein, $\mathrm{g} / \mathrm{dL}$, mean $\pm \mathrm{SD}$ & $6.79 \pm 0.71$ & $6.63 \pm 0.79$ & $6.93 \pm 0.59$ & t-test & $<.01 *$ \\
\hline Albumin, $\mathrm{g} / \mathrm{dL}$, mean $\pm \mathrm{SD}$ & $3.56 \pm 0.53$ & $3.45 \pm 0.56$ & $3.67 \pm 0.49$ & t-test & $<.01 *$ \\
\hline Total bilirubin, $\mathrm{g} / \mathrm{dL}$, mean $\pm \mathrm{SD}$ & $0.83 \pm 0.47$ & $0.88 \pm 0.45$ & $0.78 \pm 0.49$ & t-test & 0.15 \\
\hline $\begin{array}{l}\text { Lactate dehydrogenase, IU/L, } \\
\text { mean } \pm S D\end{array}$ & $\begin{array}{l}236.39 \pm \\
88.61\end{array}$ & $\begin{array}{l}256.67 \pm \\
104.41\end{array}$ & $\begin{array}{l}217.80 \pm \\
66.43\end{array}$ & t-test & $\begin{array}{l}<.01 * \\
0.0\end{array}$ \\
\hline $\begin{array}{l}\text { Aspartate aminotransferase, } \\
I U / L \text {, mean } \pm \text { SD }\end{array}$ & $\begin{array}{l}36.87 \pm \\
52.74\end{array}$ & $\begin{array}{l}43.48 \pm \\
62.64\end{array}$ & $\begin{array}{l}31.13 \pm \\
41.79\end{array}$ & t-test & 0.10 \\
\hline $\begin{array}{l}\text { Alanine aminotransferase, IU/L, } \\
\text { mean } \pm S D\end{array}$ & $\begin{array}{l}27.78 \pm \\
45.28\end{array}$ & $\begin{array}{l}28.59 \pm \\
27.63\end{array}$ & $\begin{array}{l}26.14 \pm \\
56.40\end{array}$ & t-test & 0.70 \\
\hline Sodium, $\mathrm{mEq} / \mathrm{L}$, mean $\pm \mathrm{SD}$ & $\begin{array}{l}136.60 \pm \\
4.59\end{array}$ & $\begin{array}{l}136.62 \pm \\
4.68\end{array}$ & $\begin{array}{l}136.58 \pm \\
4.55\end{array}$ & t-test & 0.96 \\
\hline Potassium, $\mathrm{mEq} / \mathrm{L}$, mean $\pm \mathrm{SD}$ & $3.92 \pm 0.55$ & $3.89 \pm 0.54$ & $3.96 \pm 0.55$ & t-test & 0.37 \\
\hline Chloride, $\mathrm{mEq} / \mathrm{L}$, mean $\pm \mathrm{SD}$ & $\begin{array}{l}101.58 \pm \\
4.87\end{array}$ & $\begin{array}{l}102.03 \pm \\
5.07\end{array}$ & $\begin{array}{l}101.19 \pm \\
4.68\end{array}$ & t-test & 0.23 \\
\hline $\begin{array}{l}\text { C-reactive protein, } \mathrm{mg} / \mathrm{dL} \text {, } \\
\text { mean } \pm S D\end{array}$ & $11.17 \pm 9.61$ & $12.63 \pm 9.86$ & $9.91 \pm 9.25$ & t-test & $0.04 *$ \\
\hline $\begin{array}{l}\text { Procalcitonin, } \mathrm{ng} / \mathrm{mL} \text {, mean } \pm \\
\text { SD }\end{array}$ & $\begin{array}{l}15.08 \pm \\
64.32\end{array}$ & $\begin{array}{l}29.73 \pm \\
94.74\end{array}$ & $3.36 \pm 9.02$ & t-test & 0.08 \\
\hline Glucose, mg/dL, mean \pm SD & $\begin{array}{l}150.94 \pm \\
65.69\end{array}$ & $\begin{array}{l}155.56 \pm \\
72.70\end{array}$ & $\begin{array}{l}146.67 \pm \\
58.60\end{array}$ & t-test & 0.38 \\
\hline Hemoglobin A1c, \%, mean \pm SD & $6.27 \pm 1.26$ & $6.54 \pm 1.56$ & $5.96 \pm 0.68$ & t-test & $0.03^{*}$ \\
\hline Urinary nitrite test (+), n (\%) & $99(50.0 \%)$ & $50(54.3 \%)$ & $49(46.2 \%)$ & $x^{2}$ & 0.25 \\
\hline \multicolumn{6}{|l|}{${ }^{\star} p \otimes 0.05$} \\
\hline \multicolumn{6}{|l|}{$\begin{array}{l}\text { CVA tenderness = costovertebral } \\
\text { angle tenderness }\end{array}$} \\
\hline bpm = beats per minute & & & & & \\
\hline
\end{tabular}

The algorism for the prediction of bacteremia driven from CHAID is shown in Fig. 1. Based on the observed results, the patients can be categorized into 3 risk groups, low (30\%), medium (30-60\%), and high (60\%). White blood cell $(\leq 21,000 / \mu \mathrm{L},>21,000 / \mu \mathrm{L})$, Chill, AST $(\leq 19 \mathrm{IU} / \mathrm{L},>19 \mathrm{IU} / \mathrm{L})$, and Albumin ( $\leq$ $3.60 \mathrm{~g} / \mathrm{dL},>3.60 \mathrm{~g} / \mathrm{dL}$ ) were included in the decision tree, and five terminal nodes were employed. According to the incidences, we divided these nodes into the following categories: low-risk, $16.3 \%$ 
incidence of blood culture-positive pyelonephritis); moderate-risk 1, 34.5\%; moderate-risk 2, 44.6\%; highrisk, $69.0 \%$; and quite-high-risk, $89.5 \%$. We evaluated the quality of this model using the ROC curve, which yielded an AUC of 0.750 and a $95 \%$ Confidence Interval (Cl) of 0.682-0.817 (Fig. 2).

The results of the chi-squared test of the qSOFA score are shown in Table 2. Patients with pyelonephritis with a qSOFA score of 2 had a significantly higher percentage of bacteremia $(p=0.04)$. We evaluated the quality of qSOFA using the ROC curve, which yielded an AUC of 0.537 and a $95 \% \mathrm{Cl}$ of $0.456-0.617$ (Fig. 3). Comparison between the AUCs in Figs. 2 and 3 indicated that the model obtained by CHAID decision tree analysis in the present study showed greater power than that obtained by qSOFA.

Table 2

Results of the chi-squared test of the qSOFA score

\begin{tabular}{|c|c|c|c|c|c|}
\hline \multirow[t]{2}{*}{ Blood cultures } & \multicolumn{4}{|c|}{ qSOFA:score } & \multirow[t]{2}{*}{ Total } \\
\hline & 0 & 1 & 2 & 3 & \\
\hline Total, n (\%) & $78(44.6 \%)$ & $67(38.3 \%)$ & $27(15.4 \%)$ & $3(1.7 \%)$ & 175 \\
\hline Negative, n (\%) & $41(44.6 \%)$ & $41(44.6 \%)$ & $9(9.8 \%)$ & $1(1.1 \%)$ & 92 \\
\hline Positive, n (\%) & $37(44.6 \%)$ & $26(31.8 \%)$ & $18(21.7 \%)$ & $2(2.4 \%)$ & 83 \\
\hline$p$ value (test: $\chi^{2}$ ) & 1.00 & 0.10 & $0.04^{\star}$ & 0.93 & \\
\hline \multicolumn{6}{|l|}{${ }^{\star} p \otimes 0.05$} \\
\hline \multicolumn{6}{|c|}{ qSOFA = quick Sequential Organ Failure Assessment } \\
\hline
\end{tabular}

Table 3 shows the results of blood and urine cultures. E. coli was the most frequent causative microorganism. 
Table 3

Results of blood and urine cultures

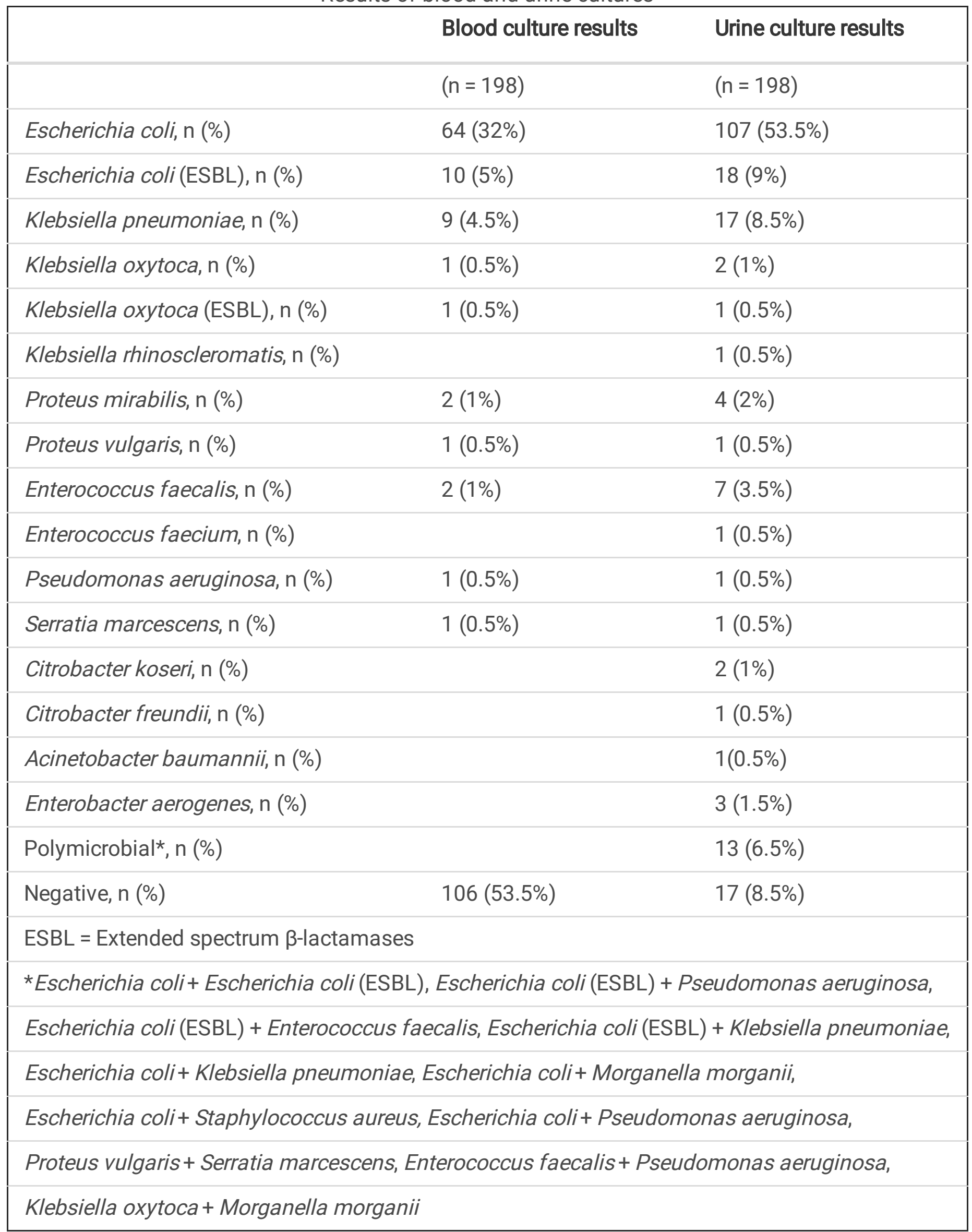




\section{Discussion}

To our knowledge, this work is the first report using CHAID decision tree analysis to perform a direct comparison between patients positive and negative for bacteremia among those with pyelonephritis. Patients with White blood cell $>21,000 / \mu \mathrm{L}$ constituted a quite-high-risk group. Patients with White blood cell $\leq 21,000 / \mu \mathrm{L}$ plus Chill plus Aspartate aminotransferase $>19 \mathrm{IU} / \mathrm{L}$ constituted a high-risk group. In contrast, patients with White blood cell $\leq 21,000 / \mu \mathrm{L}$ plus non-Chill plus Albumin $>3.60 \mathrm{~g} / \mathrm{dL}$ were at lowrisk. The AUC for the ROC curve demonstrated acceptable accuracy.

White blood cell counts (WBC), C-reactive protein (CRP) levels and procalcitonin are frequently used as markers of a systemic inflammatory reaction, but CRP and procalcitonin were not incorporated into the model for bacteremia among patients with pyelonephritis in our CHAID decision tree analysis. Several studies have shown the usefulness of CRP for estimating the risk of bacteremia in patients with neutropenia during cancer [20] or in Intensive Care Unit (ICU) patients [21]; in contrast, another study concluded that CRP was not a sensitive or specific marker for bacteremia in patients with signs of sepsis [22]. Indeed, CRP was not detected as a bacteremia factor in our preliminary research [7]. Similarly, as for procalcitonin, a severity judgment of sepsis and the utility in the prognostic value were demonstrated [23]; in contrast, another meta-analysis study concluded that procalcitonin was also not a sensitive or specific marker for bacteremia in patients with signs of sepsis [24] Our study results suggested that the increased WBC count is a timely and reliable response to bacteremia. It is important to consider obtaining blood cultures when patients have a high WBC count, even when the CRP level and procalcitonin are not elevated. Furthermore, hospitalization should be strongly considered with a WBC $>21,000 / \mu \mathrm{L}$ because these patients represented a quite-high-risk group in the present study.

Several studies have shown that the presence of chill is a powerful single predictor of bacteremia [2529]. In Japanese emergency rooms, it has been reported that the severity of chill correlates with the risk of bacteremia [30,31]. Separately, increases in AST levels are postulated to reflect rhabdomyolysis associated with the fever and early impairment of circulation. Even if WBC remains below $21000 / \mu \mathrm{L}$, hospitalization is recommended when patients have Chill and AST >19 IU/L, given that these patients constituted a high-risk group in the present study.

Another study formulated a predictive model for the mortality of patients with Staphylococcus aureus bacteremia, in which a low serum albumin level was one of the predictors [32]. Similarly, the present study identified serum albumin levels over $3.60 \mathrm{~g} / \mathrm{dL}$ as a predictor for the low-risk group. Together, these results suggest that nutritional status may contribute to bacteremia and associated outcomes. Furthermore, patients with pyelonephritis who exhibit $\mathrm{WBC} \leq 21,000 / \mu \mathrm{L}$ plus non-Chill plus Albumin > $3.60 \mathrm{~g} / \mathrm{dL}$ constituted a low-risk group in the present study, so it is possible that low-risk-group pyelonephritis patients can be treated on an outpatient basis. However, the CHAID analysis still provides only an index; it remains important that we ascertain the state of each patient carefully and decide on treatments in an informed manner. If a patient's overall clinical status is poor, hospitalization should be considered. 
The quick Sequential Organ Failure Assessment (qSOFA) now is used widely. In out-of-hospital, emergency department, or general hospital ward settings, adult patients with suspected infections can be identified rapidly as being more likely to have poor outcomes typical of sepsis if the patients have at least 2 of the following clinical criteria: respiratory rate of $22 /$ min or greater, altered mentation, or systolic blood pressure of $100 \mathrm{mmHg}$ or less [9]. In the present study, patients with pyelonephritis who presented with qSOFA scores of 2 had a significantly higher percentage of bacteremia $(p=0.04)$ (Table 2). However, based on the AUC values of the ROC curves shown in Figs. 2 and 3, the model based on the CHAID decision tree analysis (as generated in the present study) exhibited greater power than qSOFA. Thus, CHAID decision analysis was superior to qSOFA in identifying bacteremia-predictive factors among patients with pyelonephritis. In fact, other studies providing comparisons with qSOFA already have been reported $[33,34]$, and further such studies are expected in the future.

Based on the literature, E. coli is the most frequent cause of pyelonephritis [35]. In this study, E. coli also was the most-frequent causative microorganism. Possible virulence factors of this species include the ability to adhere and colonize the urinary tract, an important initiating factor in all UTIs [35]. Furthermore, in the present study, $13.5 \%$ of $E$. coli isolates ( 10 of 74 E. coli cases total) were Extended-Spectrum BetaLactamase (ESBL) producers. A previous study also showed that ESBL-producing E. coli are increasingly recognized among community-acquired infections [36]. Given that the fraction of ESBL-producing $E$. coli may increase further in the future, there is an increasing need to exercise care in the choice of medical treatment for pyelonephritis.

There were some limitations to this study. The patient population enrolled in this study was limited to a single hospital. In addition, this research consisted of a retrospective study. As a next step, a multi-center prospective study should be conducted with a larger number of patients.

\section{Conclusions}

Our results emphasize the importance of hospitalization among patients with pyelonephritis who are classified in the quite-high-risk group (WBC $>21,000 / \mu \mathrm{L}$ ) or the high-risk group (WBC $\leq 21,000 / \mu \mathrm{L}$ plus Chill plus AST > $19 \mathrm{IU} / \mathrm{L}$ ). Furthermore, it is possible that patients with pyelonephritis who are classified in the low-risk group (WBC $\leq 21,000 / \mu \mathrm{L}$ plus non-Chill plus Albumin $>3.60 \mathrm{~g} / \mathrm{dL}$ ) can treated in outpatient clinics.

\section{Declarations}

\section{Ethics approval and consent to participate}

The Ethics Committee of Juntendo University Nerima Hospital approved this study (Approval Number 2020054). This study was an observational study and written informed consent was waived due to a public health outbreak investigation by the Ethics Commission (Juntendo University Nerima Hospital). 


\section{Consent for publication}

All authors agreed to publish this study.

\section{Availability of data and materials}

The datasets used and/or analyzed during the current study available from the corresponding author on reasonable request.

\section{Competing interests}

Nothing to disclose for all authors

\section{Funding}

This research received no specific grant from any funding agency in the public, commercial or not-forprofit sectors.

\section{Authors' contributions}

SF, Al, MS and TN contributed to study concept and design. SF and Al were involved in acquisition of participants and data. SF and DK were involved in analysis and interpretation of data. SF, Al, MS, DK and TN were involved in preparation of the manuscript.

\section{Acknowledgments}

None

\section{References}

1. Ramakrishnan K, Scheid DC. Diagnosis and management of acute pyelonephritis in adults. Am Fam Physician. 2005 Mar 1;71(5):933 - 42.

2. Yamamoto S, Ishikawa K, Hayami H, et al. JAID/JSC Guidelines for the treatment of urinary tract infections and male genital infection. Nihon Kagakuryohou Gakkai Zasshi (Jpn J Chemotherapy). 2016;64:1-30.

3. Gupta K, Hooton TM, Naber KG, et al. International clinical practice guidelines for the treatment of acute uncomplicated cystitis and pyelonephritis in women: a 2010 update by the Infectious Diseases Society of America and the European Society for Microbiology and Infectious Diseases. Clin Infect Dis. 2011;52:e103-20.

4. Nickel JC. The management of acute pyelonephritis in adults. Can J Urol. 2001 Jun;8(Suppl 1):2938.

5. Ispahani P, Pearson NJ, Greenwood D. An analysis of community and hospital-acquired bacteremia in a large teaching hospital in the United Kingdom. Q J Med. 1987;63:427-40. 
6. Roberts FJ, Geere IW, Goldman A. A three-year study of positive blood cultures, with emphasis on prognosis. Rev Infect Dis. 1991;13:34-46.

7. Fukui S, Uehara Y, Fujibayashi K, Takahashi O, Hisaoka T, Naito T. Bacteraemia predictive factors among general medical inpatients: a retrospective cross-sectional survey in a Japanese university hospital. BMJ Open. 2016 Jul 7;6(7):e010527.doi: 10.1136/bmjopen-2015-010527.

8. Nobuhiro Nakamura Y, Uehara S, Fukui K, Fujibayashi H, Yokokawa TN. Useful Predictive Factors for Bacteremia among Outpatients with Pyelonephritis. Intern Med. 2018 May;15(10):1399-403. doi:10.2169/internalmedicine.9222-17. Epub 2018 Jan 11. 57.

9. Freund Y, Lemachatti N, Krastinova E, Van Laer M, Claessens Y-E, Avondo A, et al. French Society of Emergency Medicine Collaborators Group. Prognostic Accuracy of Sepsis-3 Criteria for In-Hospital Mortality Among Patients With Suspected Infection Presenting to the Emergency Department. JAMA. 2017 Jan;17(3):301-8. doi:10.1001/jama.2016.20329. 317 ) .

10. The British Thoracic Society and the Public Health Laboratory Service. Community-acquired pneumonia in adults in British hospitals in 1982-1983: a survey of aetiology, mortality, prognostic factors and outcome. Q J Med. 1987 Mar;62(239):195-220.

11. The British Thoracic Society. Guidelines for the management of community-acquired pneumonia in adults admitted to hospital. Br J Hosp Med. 1993 Mar;3-16(5):346-50. 49(.

12. Macfarlane JT, Boldy D. 2004 update of BTS pneumonia guidelines: what's new? Thorax. 2004 May;59(5):364-6. doi:10.1136/thx.2004.024992.

13. Kobayashi D, Takahashi O, Arioka H, Koga S, Fukui T. A prediction rule for the development of delirium among patients in medical wards: chi-square automatic interaction detector (CHAID) decision tree analysis model. Am J Geriatr Psychiatry. 2013;21:957-62. doi:10.1016/j.jagp.2012.08.009.

14. James N, Morgan JAS. Problems in the analysis of survey data, and a proposal. J Am Stat Assoc. 1963;58:415e434.

15. McKenzie DP, McGorry PD, Wallace CS, Low LH, Copolov DL, Singh BS. Constructing a minimal diagnostic decision tree. Methods Inf Med. 1993;32:161e166.

16. Kass GV. An exploratory technique for investigating large quantities of categorical data. Appl Stat. 1980;29:119e127.

17. Brink S, van Schalkwyk DJ. Serum ferritin and mean corpuscular volume as predictors of bone marrow iron stores. S Afr Med J. 1982;61:432e434.

18. Keks NA, McKenzie DP, Low LH, et al. Multidiagnostic evaluation of prolactin response to haloperidol challenge in schizophrenia: maximal blunting in Kraepelinian patients. Biol Psychiatry. 1992;32:426e437.

19. Zhang J, Goode KM, Rigby A, Balk AHMM, Cleland JG. Identifying patients at risk of death or hospitalisation due to worsening heart failure using decision tree analysis: evidence from the TransEuropean Network-HomeCare Management System (TEN-HMS) Study. Int J Cardiol. 2013 Feb;20(2):149-56. doi:10.1016/j.ijcard.2011.06.009. Epub 2011 Jul 2. 163 ) . 
20. Engel A, Mack E, Kern P, et al. An analysis of interleukin-8, interleukin- 6 and C-reactive protein serum concentrations to predict fever, gram-negative bacteremia and complicated infection in neutropenic cancer patients. Infection. 1998;26:213-21.

21. Póvoa P, Coelho L, Almeida E, Fernandes A, Mealha R, Moreira P, et al. Early identification of intensive care unit-acquired infections with daily monitoring of C-reactive protein: a prospective observational study. Crit Care. 2006;10:R63.

22. Byl B, Deviere J, Saint-Hubert F, Zech F, Gulbis C, Thyset J, et al. Evaluation of tumor necrosis factoralpha, interleukin- 6 and C-reactive protein plasma levels as predictors of bacteremia in patients presenting signs of sepsis without shock. Clin Microbiol Infect. 1997;3:306-16.

23. Clec'h C, Ferriere F, Karoubi P, Fosse J, Cupa M, Hoang P, et al. Diagnostic and prognostic value of procalcitonin in patients with septic shock. Crit Care Med. 2004;32:1166-9.

24. Tang BM, Eslick GD, Craig JC, McLean A. Accuracy of procalcitonin for sepsis diagnosis in critically ill patients: systematic review and meta-analysis. Lancet Infect Dis. 2007;7:210-7.

25. Hoogendoorn M, van't Wout JW, Schijf V, Dissel J. Predictive value of chills in patients presenting with fever to urgent care department. Ned Tijdschr Geneeskd. 2002;146:116-20.

26. Rector WG Jr. Fever, shock and chills in gram-negative bacillemia: clinical correlations in 100 patients. Johns Hopkins Med J. 1981;149:175-8.

27. Van Dissel JT, Schijf V, Vogtlander N, Hoogendoorn M, Wout J. Implications of chills Lancet. 1998;352:374.

28. Bates DW, Sands K, Miller E, Hibberd P, Graman P, Schwartz J, et al. Predicting bacteremia in patients with sepsis syndrome. Academic Medical Center Consortium Sepsis Project Working Group. J Infect Dis. 1997;176:1538-51.

29. Mylotte JM, Pisano MA, Ram S, Nakasato S, Rotella D. Validation of a bacteremia prediction model. Infect Control Hosp Epidemiol. 1995;16:203-9.

30. Tokuda Y, Miyasato H, Stein GH. A simple prediction algorithm for bacteraemia in patients with acute febrile illness. QJM. 2005;98:813-20.

31. Tokuda Y, Miyasato H, Stein GH, Kishaba T. The degree of chills for risk of bacteremia in acute febrile illness. Am J Med. 2005;118:1417.

32. Kobayashi D, Yokota K, Takahashi O, Arioka H, Fukui T. A predictive rule for mortality of inpatients with Staphylococcus aureus bacteraemia: A classification and regression tree analysis. Eur $\mathrm{J}$ Intern Med. 2014 Dec;25(10):914-8. doi:10.1016/j.ejim.2014.10.003. Epub 2014 Oct 14.

33. Fernando SM, Tran A, Taljaard M, Wei Cheng W, Bram Rochwerg B, Seely AJE, et al. Prognostic Accuracy of the Quick Sequential Organ Failure Assessment for Mortality in Patients With Suspected Infection: A Systematic Review and Meta-analysis. Ann Intern Med. 2018;168(4):266-75. doi:10.7326/M17-2820.

34. Redfern OC, Smith GB, Prytherch DR, Meredith P, Inada-Kim M, Schmidt PE. A Comparison of the Quick Sequential (Sepsis-Related) Organ Failure Assessment Score and the National Early Warning 
Score in Non-ICU Patients With/Without Infection. Crit Care Med. 2018;46(12):1923-33.

doi:10.1097/CCM.0000000000003359.

35. Roberts JA. Etiology and pathophysiology of pyelonephritis. Am J Kidney Dis. 1991 Jan;17(1):1-9. doi:10.1016/s0272-6386(12)80242-3.

36. Calbo E, Romaní V, Xercavins M, Gómez L, Garcia Vidal C, Quintana S, et al. Risk factors for community-onset urinary tract infections due to Escherichia coli harbouring extended-spectrum betalactamases. J Antimicrob Chemother. 2006 Apr;57(4):780-3. doi:10.1093/jac/dkl035. Epub 2006 Feb 21.

\section{Figures}

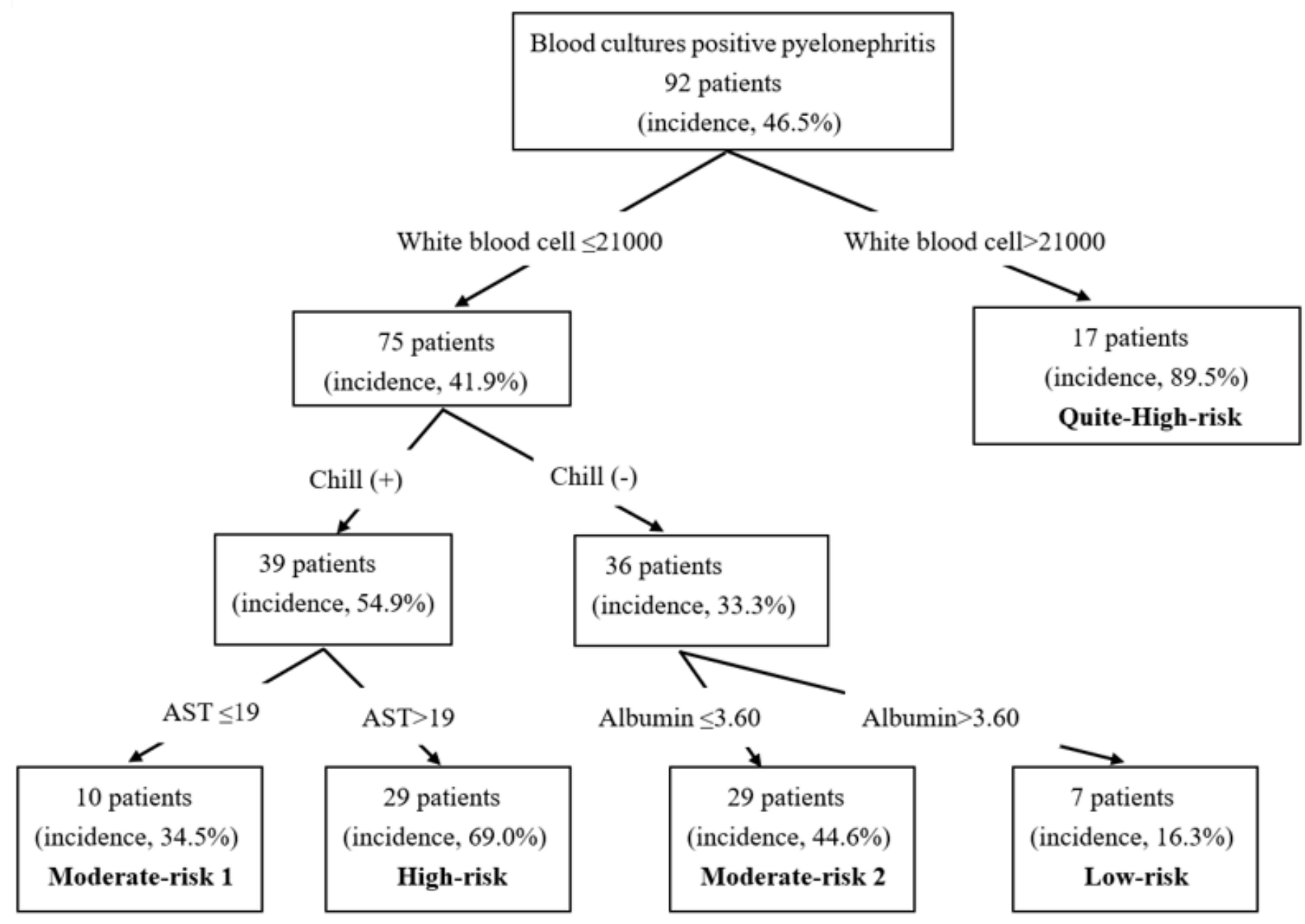

\section{Figure 1}

The algorism for the prediction of bacteremia driven from CHAID. Categories were defined based on bacteremia incidence values as follows: low-risk group, $\leq 30 \%$; moderate-risk group, $40-60 \%$; high-risk group, $\geq 60 \%$. 


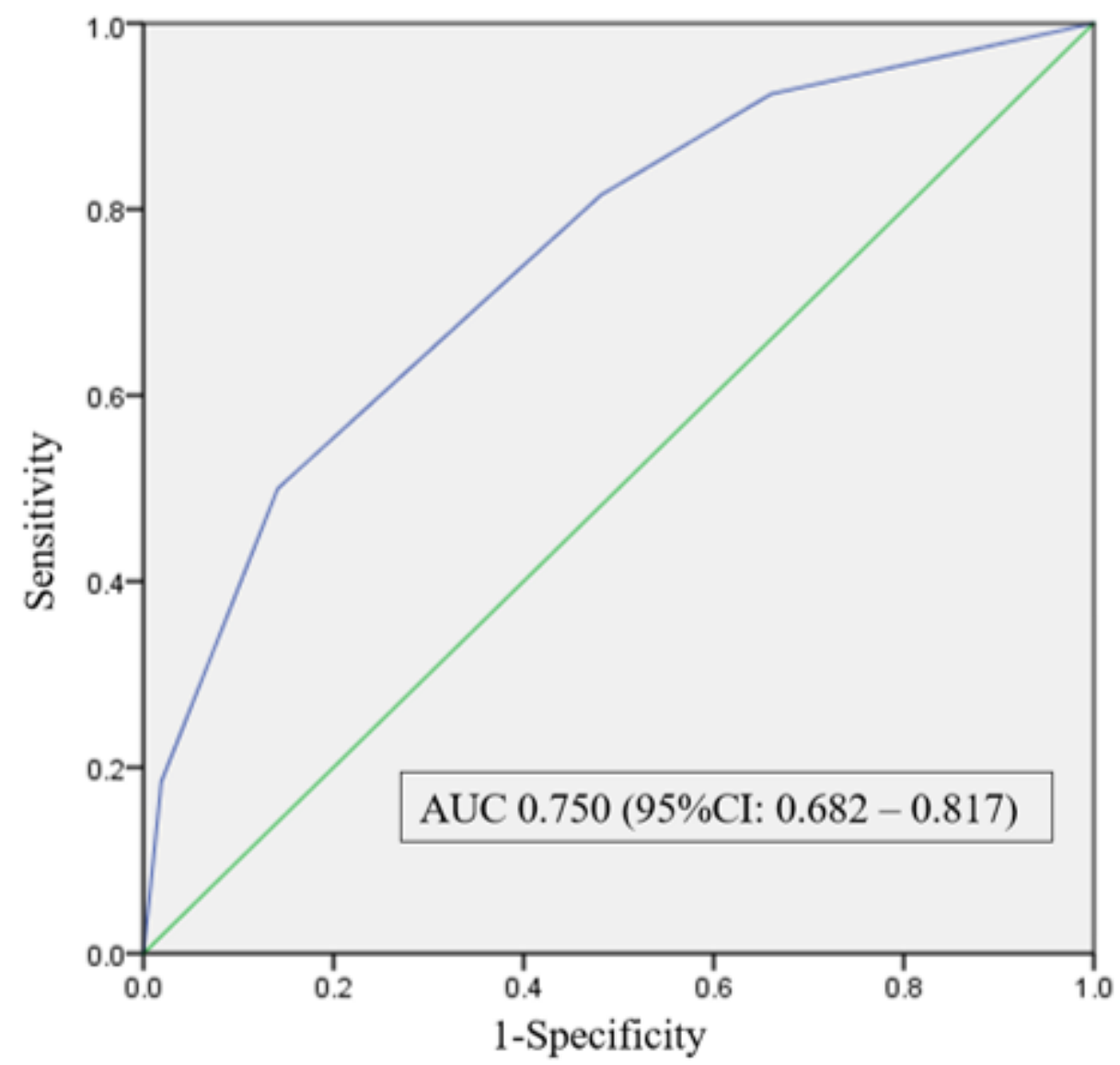

Figure 2

Receiver operating characteristics curve of CHAID-formulated decision tree for the positive risk factors for bacteremia among patients with pyelonephritis. 


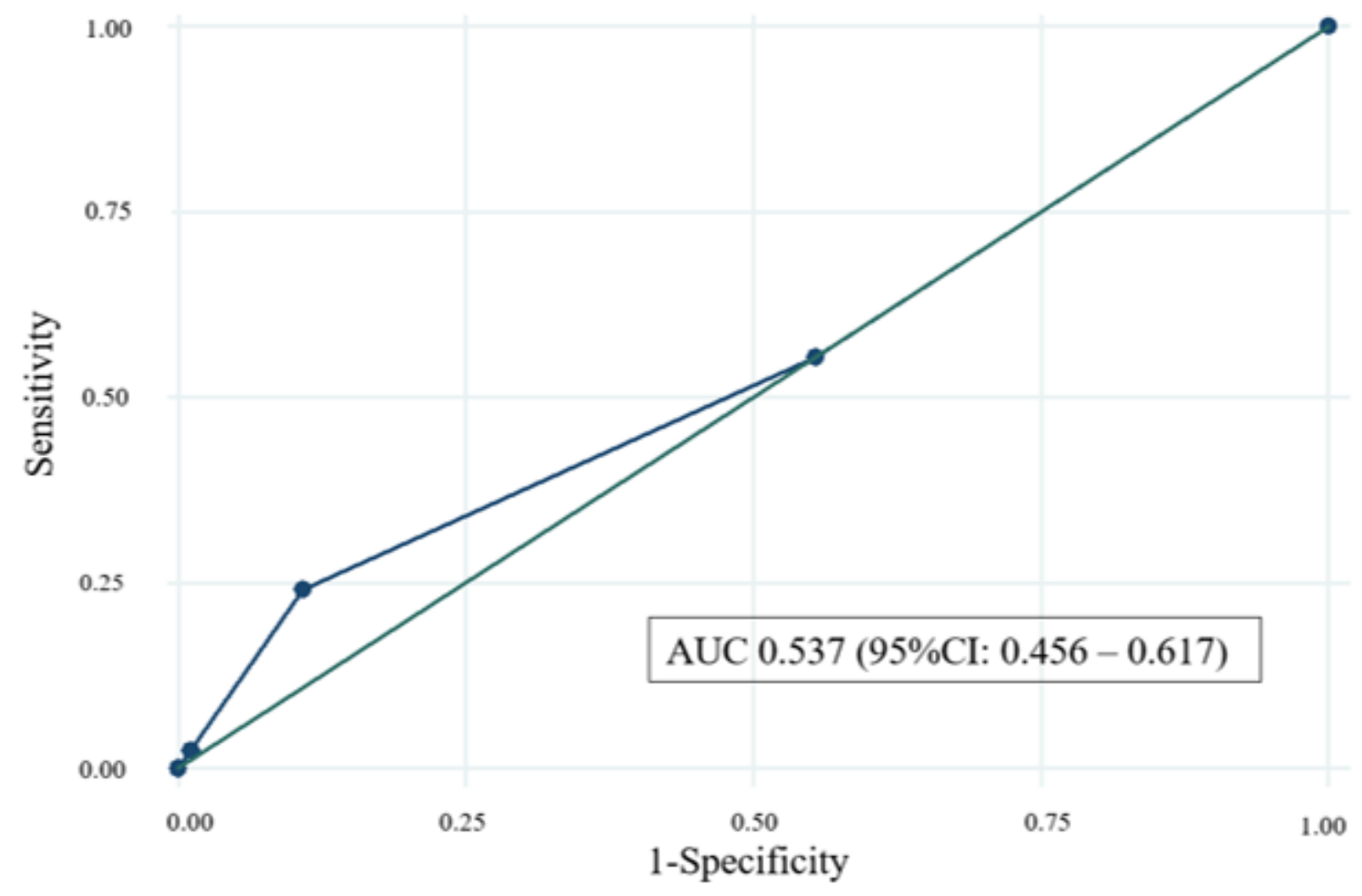

Figure 3

Receiver operating characteristics curve of the quick Sequential Organ Failure Assessment (qSOFA) for the positive risk factors for bacteremia among patients with pyelonephritis. 